\title{
What do GDPs think of evidence-based practice?
}

\author{
General dental practitioners' knowledge of and attitudes towards evidence-based practice.
}

\section{A. Iqbal and A-M. Glenny Br Dent J 2002; 193: 587-591}

\section{Aims}

To assess general dental practitioners' understanding of, and attitudes towards, evidence-based practice (EBP).

\section{Subjects}

A random sample of general dental practitioners currently practising in the North West of England.

\section{Method}

A cross-sectional survey using self-administered, structured, postal questionnaires in January 2001.

\section{Results}

A majority of the respondents had some understanding of technical terms associated with EBP. Only 29\% (60/204) could correctly define the term EBP. When faced with clinical uncertainties 60\% (122/204) of general dental practitioners turned to friends and colleagues for help and advice. Eighty one percent of respondents were interested in finding out further information about EBP (165/204). Barriers to its use included a lack of available time and financial constraints.

\section{Conclusions}

EBP is not a concept that every dentist is familiar with, however, the general dental practitioners surveyed were enthusiastic and expressed a desire to find out more information on EBD. It appears to be the right time for an educational program targeted at GDPs to enhance their knowledge and use of EBD in everyday practice.

\section{IN BRIEF}

- This paper gives an insight into evidence-based dentistry.

- Determines the use and knowledge of evidence-based dentistry by general dental practices.

- It appears to be the right time for an educational programme targeted at GDPs.

\section{COMMENT}

If the principles of evidence based practice (EBP) are to impact on the provision of dental care, providers need to be aware of and have a positive attitude towards the processes involved.

As most dental care in the UK is delivered by general dental practitioners (GDPs) it is important that this section of our profession is well informed and keen to apply the concepts of EBP to address everyday clinical problems. In this respect the study by lqbal and Glenny is asking the right questions of the right people.

In their introduction they stress the importance of systematic reviews in providing the highest level of evidence on which to base clinical decisions and acknowledge the role of the Cochrane Oral Health Group in co-ordinating the production of systematic reviews of randomised controlled trials (RCT's) related to oral health.

A random sample of GDPs working in the North West of England was questioned. The sample is likely to be representative of the GDPs working in this area but whether their views and attitudes are the same as GDPs throughout the UK is uncertain. I found the demographic breakdown of the respondents interesting in that over three quarters were male and nearly two thirds had been in practice for more than 15 years. Although graduates of most UK dental schools were represented, half of the respondents had graduated in the North West.

When asked about their knowledge of EBP terms the respondents generally underrated themselves, as far more of the definitions of EBP terms given by the respondents were correct than their self reported ability to define these terms. However, I found it disappointing that nearly three quarters of respondents were unaware of the term Cochrane Collaboration.

Despite most respondents grading the importance of $E B$ dentistry in general practice as important and claiming to change their practice in light of research findings, most respondents asked friends or colleagues for help when faced with clinical uncertainty and only $14 \%$ consulted a text book or electronic database for information.

In general, I found the results of this well conducted study encouraging. Most respondents were aware of key terms associated with EBP, rated EBP as important and appeared keen to find out more about EBP. I think that there is a large potential for addressing this unmet educational need of GDPs and hope that by increasing the awareness and knowledge of EBP patient care will improve.

Jayne E Harrison, Consultant Orthodontist, Liverpool University Dental Hospital.

Member of the Editorial Team of the Cochrane Oral Health Group. 